\title{
ScienceHumanities: Theory, Politics, Practice
}

\author{
Martin Willis, Keir Waddington and James Castell ${ }^{1}$
}

\section{The Challenge of Being Challenge-Led}

In January 2015, Nature offered an editorial on the relationship between the sciences, the social sciences and the humanities (Campbell and Dhand). Perhaps with a desire to begin a new calendar year with a fresh and urgent perspective, the editorial argued that "Governments that want the natural sciences to deliver more for society need to show greater commitment towards the social sciences and humanities" (5). It went on to suggest that present systems and policies - of funding and strategic support, both institutionally and governmentally - may destabilise the potential for the different disciplines to work together. Despite this, the editorial concluded that there is a widelyheld view, even within these institutions and relevant funding bodies, that "the mutual framing of challenges is the surest way to overcome the conceptual diversities and gulfs that can make such collaborations a challenge" (5). There are two sets of challenges to be addressed in other words: the challenges themselves and the challenge of the new modes of collaboration necessary to address them. Too often, as we suggest here, these challenges solidify disciplinary boundaries rather than enabling new ways of working together.

From an ageing population to climate change, the challenges faced by contemporary society are multifaceted and on an immense, often global, scale. Mark Wolpert, the UK Government Chief Scientific Advisor at the time of the Nature editorial called them "complex, uncertain and highly contested" (9). They demand a new sense of joint enterprise that actively sustains multiple responses; rather than a denial of a right to involvement through a restrictive (and historically and culturally constructed) notion of the boundaries of expertise. As Nature's editors noted, "if you want science to deliver for society, through commerce, government or philanthropy, you need to support a capacity to understand that society that is as deep as your capacity to understand the science" (Campbell and Dhand 5). Such an aspiration requires new ways of thinking about the knowledge produced within the humanities and social sciences, as well as new ways of collaborating with the sciences.

The challenges facing such work are multifarious, however. Primary among these is that existing relationships and constructions of a hierarchy of expertise and utility often function to undermine productive research collaboration. Before a challenge-led approach to local and global problems can be constituted appropriately the challenges to disciplinary equality and collaboration must be addressed. It is vital that the various disciplines in the humanities and sciences work together to face these challenges. Too often, and too readily, the different disciplines seek out scientific collaboration rather than working also with other closely cognate subjects. Too rarely do literary critics collaborate directly with anthropologists, or philosophers with sociologists, and all four with one another and disciplines from the sciences. Moreover, there has been a race towards specialisation in examinations of science. Humanities scholars, for instance, have largely chosen to engage with very particular fields of scientific endeavour. This is clear in the splintering of disciplines into specific research niches: medical humanities, literature and science, and the environmental humanities are fine examples of this process. These are enormously valuable areas of research expertise, but they do not always share knowledge with one another or ask how their 
own expertise and experience might benefit similarly constituted research networks. There is value, then, in the humanities working across the various disciplines of which it is constituted; most especially in the sharing of epistemic understanding of the nature of collaborative knowledge itself.

In this article, we offer a new and necessary re-evaluation of the nature of disciplinary knowledge and expertise, and its collaborative pitfalls and potentials. We explore a present lacuna in research: the lack of focus on how scholars both think about and practice this work across and between the humanities and the sciences. We do this by thinking theoretically, politically, and through practice. We call this triangulation the ScienceHumanities, a single identifier that even in being written on the page throws separate disciplines into close proximity. It represents not a relativist campaign against the sciences that repeats familiar tropes or ways of working, but a widening of focus and a recognition of the value of plurality. ScienceHumanities offers a new way of conceptualizing the most fundamental challenge of multiple and disparate disciplines working together. We argue here that it is only by solving the problems of their own difference and by finding innovative ways of working which do not privilege particular epistemologies that disciplines might be able to meet together to tackle what have been framed as "grand societal global challenges" (Ulnicane). In the first part of the article, we set out the theoretical ways of approaching the ScienceHumanities before, in the second part, critiquing the current institutional and cultural politics of collaboration to generate a frame within which new practices can emerge. In the final part of the article, we examine some examples of current practices of working and suggest different forms of collaboration. We conclude by offering a manifesto for ScienceHumanities theory and practice.

\section{Theory}

Reflecting in 2004 on the "tired routines of most social theories", Bruno Latour described how "one after the other, we witnessed that the black boxes of science remained closed and that it was rather the tools that lay in the dust of our workshop, disjointed and broken" ("Why has critique run out of steam?" 242). As a way out, he turned to Heidegger's etymological emphasis on gathering or association in the word "Thing" to suggest the need for "multifarious inquiry drawing on a wide range of tools in the humanities and the social sciences" (245). Latour argued for a new mode of critique to interrogate the "stubbornness of matters of facts" (and things) that he associated with the sciences (246). But where he highlighted problems and posed questions, Latour offered few solutions. By the time he attended to this again in 2010, he focussed on appeasing differences between disciplines and moved away from critical perspectives and towards what he called matters of concern ("Compositionist Manifesto" 478-79). This approach was put into practice in the multi-user online course that Latour developed under the title "Scientific Humanities". The course offered students familiar training in some of the key principles of Science and Technology Studies (STS) while claiming that the scientific humanities "means the extension of interpretative skills to the discoveries made by science and to technological innovations." The aim of the course was to "equip future citizens with the means to be at ease with many issues that straddle the distinctions between science, morality, politics and society" ("MOOC on Scientific Humanities"). It seems to us that the direction of travel of Latour's thinking and practice ought to be even more inclusive in calling on the humanities and social sciences. As we argue here, we ought to be even more theoretically-engaged - rather than at ease - in our interrogation of the ways in which the humanities and the sciences combine to make knowledge. This, however, 
demands further conceptual examination of foundational questions of epistemology, authority and expertise.

The disciplines of philosophy and STS have traditionally provided a fertile field for considering these conceptual categories. Early work in these areas laid claim to intellectual approaches from Marx to Douglas's cultural anthropology to consider the sciences' knowledge claims and their contingent nature. Both social constructionism and Actor Network Theory (ANT) have emerged as methodological approaches that scholars have taken up as tools to unpick the "black boxes of science". These methodologies seemingly cut across disciplines, with ANT benefitting from "epistemological movement away from the cultural to the material, from questions of representation to matters of process, practice, and effect" (Gunn and Owens 491). In raising questions about materiality and the conditions for the emergence of innovation, ANT offered ways into thinking about people, things, and ideas as material and nonmaterial agents that appealed to a broad range of humanities disciplines interested in science. ANT represented a tool to consider the constantly changing, contingent, and heterogeneous nature of scientific production, the actors, objects, and networks involved, and their linkages to everyday practices as well as the imagination (Latour, Reassembling the Social). This approach encouraged the use of thick description to address the multiple materialities of science and how scientific epistemologies have been giving meaning through the attention and practices of scientists. Such familiar tools enabled a view of science as something layered, complex, multifaceted, negotiated, and contingent, and how its development involved material, technical, juridical, political, discursive, social, and imaginary elements.

Philosophers of epistemology - Richard Rorty primary among them - had already shown how the sciences employ their own cultural forms and communities to construct "facts" while leaving the humanities to issues of "value" (Rorty 35). This separation of fact from value, paralleled by the historic separation of the sciences from the humanities, led to wider divisions working around these originating binaries. By the start of the twentieth century, the sciences had acquired the character of truthfulness and objectivity while the humanities offered aesthetic pleasure and subjectivity. These constructions, for Rorty, are nothing but knots that continue to bind the disciplines unhelpfully to outmoded rhetoric. If these were to be overthrown, Rorty argues, there would be no need to differentiate between disciplines in the same ways: "terms which denoted disciplines would not be thought to divide 'subject-matters', chunks of the world which had 'interfaces' with each other. Rather, they would be thought to denote communities whose boundaries were as fluid as the interests of their members" (45). Drawing on the language of computational science, Rorty calls this epistemic shift the "heyday of the fuzzy", a conceptual category that revels in open encounters, unforced agreements and reciprocal loyalty (45). This argument has been rather lost in contemporary theoretical discussions of disciplinary collaboration, but has begun to emerge under a different terminology in very recent theoretical understandings of interdisciplinarity.

Following Rorty, Latour, and work within STS and the history of science, scholars now understand how science was the result of a series of complex inter- and intra-actions, but there remains less of a sense of how such tools enable "multifarious inquiry" across the humanities and the sciences. This has been a consideration (often implicit) at the heart of theoretical examinations of the epistemological basis of interdisciplinarity, or as Barry and Born put it, how to "understand interdisciplinarity less as a unity and more as a field of differences, a multiplicity" (5). Following the intellectual and economic success of the term interdisciplinary there has been a 
proliferation of prefixes to disciplinarity (Osborne 4-9). Postdisciplinarity, for example, may dissolve many unproductive boundaries but it fails to recognise adequately the role of disciplinary difference and historicity in shaping current objects of concern. Multidisciplinarity captures the sense of many disciplines working together but maintains the separation of disciplinary expertise and often does not seek out any change or alteration for those disciplines within the experience of collaboration. Interdisciplinarity seems more attuned to this cross-pollination of knowledge, but is arguably limited to working between two or more disciplines and between two or more researchers. There have even been recent attempts to avoid disciplines altogether. Advocates for undisciplinarity aim to go their own way "without worrying about working outside of what histories-of-disciplines say is proper "work" (Marshall and Bleeker 219). Such a perspective unrealistically denies the influence of disciplinary authority as well as the profound importance of disciplinary expertise necessary to all collaborative work.

Transdisciplinarity, however, offers a more supple vision of how disciplines might interact. Perhaps because its most recent incarnations emerge from queer studies, work on the meanings of trans provide both theoretical and also practical, even pragmatic, modes for thinking through and working with difference. For Rogers Brubaker, transgendered identity leads us to understand much more completely how trans can be both a "trans of between" where one defines "oneself with reference to the two established categories, without belonging entirely or unambiguously to either one, and without moving definitively from one to the other" and a "trans of beyond" where there is a "claim to transcend existing categories" (10). It is clear how this new conception can be taken up in disciplinary terms. Indeed, it both supports the complexity of multiplicity while showing how different epistemes might be productively inter-related. It both reflects the kind of "entanglements" (Fitzgerald and Callard 39) important for understanding the challenges facing society and looks to the profound difficulties of doing so identified by Latour and Rorty.

Transdisciplinarity therefore holds in productive balance the fact that knowledge-making not only requires the content of more than one discipline but also an awareness of the limitations, mediations, contingencies, and shared practices of those disciplines. In other words, to explore the intersections between the sciences and the humanities, we need to think across and beyond disciplinarity; we need to embrace the fuzzier areas that are both in-between and on the far horizon. Rather than suggesting this is a one-off process, we need to do this regularly and historically. In this, we agree with Latour's desire to recalibrate his "equipment and training" in the face of new circumstances ("Why has critique run out of steam?" 231). This way of theorizing permits a sensitivity to the full range of such thinking as it is already taking place within disciplines. It also allows a forging of new ways for humanities scholars and scientists to ask questions and to work on problems together, regardless of whether they share a "history of shared formalisms and rule systems" (Bod 376). It demands equally the particular expertise of the humanities in investigating the mediations and contingencies of knowledge production and also an awareness of its blind spots, what Robert Procter and Londa Schienberger have described as agnotology or a way of describing "the cultural production of ignorance" (1). Such an approach allows us to ward against what the urban planner and social activist Peter Marcuse refers to as "one-dimensional language" or the quiet acceptance of linguistic simplifications that flatten out differences. Or as the evolutionary biologist Steven Jay Gould warned, connecting the sciences and the humanities should aim for wholeness but "cannot achieve the goal by shearing off differences" (5). 
The ScienceHumanities as a label reflects the need for pluralism embodied in transdisciplinarity as a way of thinking about the emergence and development of highly various modes of thinking. The use of a single term - ScienceHumanities - and internal capitalisation was born from our experience of being unable to find useful collaborations in web searches when using the terms science and humanities in their familiar linguistic structure as individual words. These generate so many millions of hits as to make searching useless and knowledge-making impossible. The putting together of the two words, by contrast, allows collaborations both to be discovered in the digital environment and reformulated. This led us to recognise more explicitly the concomitant and beneficial theoretical effect of this conjunction and how it avoids prescribing or caricaturing forms of relation or separation between the two. In other words, it stops the ScienceHumanities from relying on what Wordsworth called, albeit in a very different context, "pre-established codes of decision" (739). Instead, the ScienceHumanities favours responding to new disciplinary configurations and new objects of study in their minute particularity but also with an eye to their broadest significances. The ScienceHumanities carves out a privileged space for the humanities to interrogate scientific topics with a focus on themes with which it already has considerable expertise, including the centrality of culture, history, aesthetics, and the imagination. Such an approach inevitably raises questions about the politics of how we undertake this work, and it is to that politics that we now turn.

\section{Politics}

Between theory and practice, there is a politics of working. In earlier efforts to work across and between the humanities and the sciences, the notion of the "two cultures" had taken on political significance beyond the weight of the arguments that C. P. Snow put forward in his 1959 Rede Lecture, The Two Cultures and the Scientific Revolution. Frequently misread as a totemic statement about the relationship between the sciences and the humanities, over the last half century the "two cultures" paradigm has been regularly re-purposed in the name of a wide range of causes (see Sokal and Bricmont). Snow's Two Cultures has become a common point of reference for what is imagined as a "gulf of mutual incomprehension" (Snow 4) and hostility between the sciences and humanities and has been used to support particular constructions of disciplinary hierarchies, often for political ends. A misreading of the "two cultures" by polemicists and policymakers repeats in the present the claims of the past and, as Stefan Collini suggests, fashions the humanities and the sciences as stable entities (Collini lxv).

Such modes of thinking in political, policy, and academic debates have enabled an unproductive view that the humanities come after the sciences and relegate them in political, funding, or disciplinary terms to a perceived position of relative inferiority. Often overlooked is Snow's subsequent work. Here he drew attention to the importance of investigating human existence through tools that were to become central to the humanities (Snow, "The Two Cultures: A second look"). Snow's second look led him to make a number of fundamental alterations to his initial formation of the "two cultures". First, he revised his definition of culture. Avoiding the divisionary status he accorded culture in his earlier work, he characterised it afresh as an aspect of human existence we all share. Culture, Snow argued, emerges from a "curiosity about the natural world" that marks "the most specifically human of all human qualities" and which cannot be regarded as separating the sciences from literature (62-3). This understanding of cultural harmony, Snow explained, reminds us that neither the scientific system nor the traditional literary approaches are "adequate for our potentialities, for the work we have in front of us, for the world in which we ought to 
begin to live" (64). Second, Snow questioned his decision to choose the number two. He accepted that "a third culture", the social sciences, was beginning to make an impact on disciplinary relations (70). He suggested that this had the effect of softening "some of the difficulties of communication" between the sciences and humanities (71). In turn, Snow concluded, relationships will cease to be antagonistic and new research will emerge which will be "of importance for our intellectual and moral health" (71). We need to be cautious about such easy harmony, especially if it fails to engage adequately with legitimate points of difference within and across cultures. Nevertheless, Snow's second look is usefully distinct from the Two Cultures as a characterisation of disciplinary difference that emphasises interacting multiplicities rather than polar oppositions.

Notwithstanding Snow's subsequent (and telling) rejection of binaries, the explanatory burden placed on the supposed humanities-versus-sciences dichotomy aided by constructions of disciplinary worth or access to political or economic capital - has structured or delimited the potential interactions between the humanities and the sciences. An enduring political rhetoric that useful knowledge comes from technical or scientific skill, the ambiguous ways in which the term the humanities has been used, and a restricted understanding of the knowledge base of disparate humanities disciplines, has allowed the propagation of naïve assumptions about the expertise of humanities scholars. The most damaging of these is the mistaken belief that many humanities disciplines do not have specific expertise but only opinions; assumptions that reflect an unconscious belief that aesthetics, the imagination, or the temporal do not lead to the kinds of hard truths uncovered by the sciences.

This framing of the "two cultures" neglects the historical context and the political and ideological elements of Snow's lecture and the resulting controversy (see Ortolano). A key component of Snow's argument was the role of expertise in the formulation and execution of public policy. An awareness of these claims allows a different use of Snow: one that rejects antagonistic modes of thinking and instead raises important questions about the nature and role of authority and expertise - questions that have been central to the history of interactions between different sciences and different humanities. A recalibration of how authority and expertise function and are employed is an essential component of working at the intersections of the humanities and the sciences. Humanities scholars are well placed to use their expertise to look critically beyond historic and existing discourses of power and authority to challenge the idea that the humanities are there only to be a supportive friend to the sciences.

The ScienceHumanities seeks to break away from a construction of the Two Cultures as a foundational text and from a mischaracterization of the forms of knowledge and roles that the humanities have within collaborations with the sciences. Collapsing the false divides between the humanities and the sciences, as Snow began to do in his second look, encourages us additionally to think further about other unproductive binaries that mark the politics of knowledge production, authority, and expertise. Snow addressed the relationship between advanced and developing countries and the nature of progress and modernity (Two Cultures). Humanities scholars have led the way in rethinking the assumptions embedded in such assessments. Through critiquing how we deploy modernity, they have shown how such assumptions reinforce notions of Western superiority. The influence of postcolonialism and work on "multiple" or "blended" modernities reminds us of the problem of perspective in the narratives we construct around the sciences and the humanities, as well as asking us to think again about the framing of the global challenges we discussed in the introduction to this article (AHR Roundtable: Historians and the Question of "Modernity"). 
Thinking in these ways encourages us to ask whose science and whose humanities are we thinking and writing about?

In political debates about the value and role of the sciences the answer is often a Westernized version of science, which in turn is often particularized as universal. The employment of postcolonial critiques, or the notion of "multiple" or "blended" modernities, challenges the assumptions embedded in the theories and practices used in our approaches to the humanities and the sciences. In particular, they challenge how these assumptions inform the creation, adoption and employment of our theories and practices. A ScienceHumanities approach needs to be informed by such an understanding so that it embraces different influences, points of departure, and alternative geographies beyond Britain, Europe, and North America. Such an approach implies a resistance to reducing the sciences to a feature of Western modernity or to simplified claims about nature based on a sense of Western epistemological solidity. It is also an approach more attuned to the inequalities of knowledge production and subsequent influence, especially as those are mapped onto global hierarchies of power. An example of pre-existing work that has started to take these ideas seriously is writing focussed on the limits of disciplinary knowledge and the inequalities of damage in the Anthropocene (Nixon and Chakrabarty).

The implications of such macro concerns are paralleled at various micro levels: particularly the institutional and the personal. The former often favours competition that reinforces antagonistic binaries. These largely reflect institutional structural legacies rather than current research thinking. For instance, the initial exclusion of the humanities from the Canadian Foundation for Innovation revealed the assumptions made about research infrastructures that focused only on the needs of science and technology (Gaffield 7). While support for interdisciplinarity - a term employed across the globe and within research institutions of all kinds - acts as a vision of an integrated research culture in which different ways of knowing and thinking offer strategies for addressing similar or joint questions, how this is achieved has not been understood in the same way by these different institutions (British Academy 57). For example, a recent UK survey of interdisciplinary research found that it occurred most often between different scientific disciplines rather than across more distant disciplinary divisions. Traditional humanities disciplines, such as history, appeared to undertake far less interdisciplinary research; a finding that suggests access to disciplinary collaboration is more difficult for the humanities than it is for the sciences within present institutional structures (Elsevier 33-6). Certainly the more distant the perceived disciplinary distinctions the more difficult collaborative research is presumed to be. This is true also at the level of the individual researcher. Political structures militate against the active researcher working with disparate disciplines and in ways that may demand shifting from traditional or common practices. University departments often employ subject-specific knowledge in assessing individuals for career advancement, while funding bodies are far more likely to support research that falls most readily into already-defined categories.

To overcome these limiting political cultures, it is vital that the humanities and the sciences are able to articulate the value of collaborative practice. Although it is widely accepted that the most important questions require interdisciplinary intervention (HEFCE et al.), this does not provide the necessary methodological collaborations which we argue transdisciplinarity permits. Only in turning to new ways of working together will the present political disincentives begin to dissolve. But what practices should be adopted to do this? 


\section{Practice}

Institutional politics clearly play an influential role in the organisational structures of the kinds of research that we see as paradigmatic of the ScienceHumanities. In acknowledging this, it is also important to recognise that the ScienceHumanities was itself conceived within, and continues to belong to, just such an organisation. That is, the ScienceHumanities functions as a research network supported by a university as well as enacting a specific set of theoretical, conceptual and political positions (Castell et al., "Cardiff ScienceHumanities"). While this inevitably serves as a reminder of the privileged position from which we attend to the knowledge-making potential of transdisciplinary interrogations it also shows how the integrity of geographical proximity can be a pragmatic starting point for practice-based intervention.

Indeed, many of the practices that we seek to promote often start in shared situations. In some cases, this may take the form of work-in-practice that is determined by the particular geographic space within which it takes place. This is true, for example, of recent projects on the Anthropocenic landscape of Wales and on the therapeutic implications of portrait painting for cancer patients (Griffiths et al.; Gilbert et al.). Although very different from one another both projects required specific spaces within which to conceptualise their interactions and to develop new epistemes. In two other cases, again focussed on medicine (specifically on different understandings of dyspnoea or breathlessness) and on the Anthropocene (concerning the disciplinary meaning of that very term), the shared spaces are conceptual or linguistic (Oxley and Macnaughton; Ellis et al.): how should terms such as the Anthropocene or breathlessness be defined, and who has the right to define them?

There is much to be learned from existing practices, and not only in how they negotiate their own locale. To do this, we offer an analysis of the four projects introduced above. Two of these projects attempt to discover new knowledge based on interactions between the medical sciences, social sciences and humanities. The other two consider the creation of knowledge in and between the physical sciences, the social sciences and the humanities. They represent only a small sample of the many projects underway internationally that might make a valid claim for inclusion here. Findings from pre-existing projects offer a form of case law from which precedent might be drawn. While we have no intention of acting in an adjudicatory way in writing about these projects, we will draw upon their implications in conceiving future directions for the ScienceHumanities.

The first pair of practices are two projects focussed on studies of the Anthropocene, albeit at very different scales. The first is a global intervention into Anthropocene policy (Ellis et al.). The second is a more modest investigation of the anthropogenic landscape of the mid-Wales uplands (Griffith et al.). The global project published its results in the science journal Nature, the Welsh project in GeoHumanities (a journal that indicates its cross-disciplinary pedigree). Both projects are underpinned by a similar desire to see a more distributed understanding of the Anthropocene that acknowledges the important role of a number of different disciplines. Like many others, Griffiths et al. argue that "The ethical, philosophical, and moral dimensions" of the Anthropocene debate "have taken it beyond the sciences, arguably inspiring a shift in the arts, humanities, and social sciences" (1) while more stridently Ellis et al. contend that the small number of disciplines claiming authority over studies of the Anthropocene "instil a Eurocentric, elite and technocratic narrative of human engagement with our environment that is out of sync with contemporary thought in the social sciences and the humanities" (192). 
Despite the clear reservations on issues of shared endeavour both projects promote optimism in seeing the possibility for conjoined working. The global project makes a case for a stable multidisciplinary foundation as a necessary starting point, while the Welsh project focusses to a greater extent on joint immersion within the site of research itself, so that they "observed, discussed and mused on the landscape" in the company of one another (Griffith et al. 2). These are clear expressions, very literal in the second example, of the common ground that provides the impetus for common purpose. To be purposeful is also an enactment of specific research practices. For Ellis and his collaborators, it is that "scholars from all disciplines" approach the study of the Anthropocene "with the seriousness it deserves" (193). In this context, seriousness refers to rigour, to methodological precision, and to subject-specific knowledgemaking. As the Welsh project concluded, their co-engagements with the landscape provided "opportunities for the creative writer to experience the close observation of the scientist and for the scientist to experience the speculation and astonishment more commonly associated with artistic practice" (Griffith et al. 11).

Although there are disciplinary alignments emerging in these examples, both projects hinted at ongoing problems of equity which illuminated disciplinary power imbalances. For Griffiths, the involvement of creative practitioners in the study of the Anthropocene was useful as a way of "encourag[ing] society to take action", with their role as a handmaiden for scientific knowledge rather than as a research tool that might itself contribute to the study of the Anthropocene (12). For Ellis, too, the formation of a multitude of disciplines all working together was undermined by the power of the sciences within the research group, whose membership reached thirty-seven but included, for instance, only "one historian" (193). This led their research to focus "almost exclusively on geological deposits" to the detriment of other disciplinary interests (193). Implicit in both projects is a view that the sciences arrived first on the Anthropocene and their claim to primacy remains potent and drives exclusivity. This conclusion rather unpicks the optimism of common problems addressed by multiple disciplines attuned to one another's expertise.

Does this remain true of the medical sciences? Medicine has historically been more closely associated with the arts than geology and might therefore have a different perspective on collaborative practice, especially given the way the medical humanities has emerged as a discipline. Two projects aimed at combining medicine with the social sciences and humanities published their findings at a similar moment in 2016. The first examined portrait painting in cancer treatment in the US (Gilbert et al.). The second considered breathlessness as both a medical condition and a phenomenological experience in the UK (Oxley and Macnaughton). Foundational distinctions appear early in the descriptions of these projects. Gilbert's group implicitly align their mode of address with the disciplines of medicine. They write, for example, of the defamiliarizing effects of what, from that perspective, was an unusual methodological practice, although one quite common across the arts and humanities: "Due to the qualitative nature of the study, no one knew what to expect; yet, all parties continued in the project, demonstrating acceptance of the uncertainties inherent in the process" (59). By contrast, consciousness of the different epistemologies of a number of disciplines was, for Oxley and Macnaughton, central to the study's practice. They describe their project as "integrated multidisciplinary work" (256), making a case for this being absolutely essential to its success; claims which they see as integral to their vision of the medical humanities (Durham).

In spite of preliminary disciplinary differences both projects regard as vital the interconnectedness of the medical sciences with the humanities. The similarity, even 
the empathic alignments of disparate disciplines, are drawn out by Gilbert's group through the active craft work that each participant employs. For them, "The art and science of the practice of both portraiture and medicine requires practitioners to be productive and imaginative, to do and feel, and to care and to fix" (62). While this vision of disciplinary interaction depends upon practice, as well as the historically contingent connection of medicine to an art, Oxley and Macnaughton understand collaboration rather differently. In their project dyspnoea (breathlessness) was itself a "multidisciplinary construct" (257) that demanded investigation from a number of disciplines working towards a "shared goal" (260) of understanding dyspnoea holistically. There are fundamental differences here in how collaborations between disciplines function. For Gilbert and his colleagues, it is the commonalities found through an experiential understanding of working practice that leads to joint knowledge-making. For Oxley and Macnaughton, collaboration is rooted in the common object of study, dyspnoea, which embodies multiple disciplines and constructs a shared frame of reference around which the medical sciences, social sciences and humanities coalesce.

There are fissures, still, in each collaborative effort, regardless of whether one or other seems most robust as a methodology. While Gilbert's group saw art practice and medicine as similar crafts, the results of their project articulate a combined knowledge that is valuable only to the medical field. The product of the collaboration has a market only within one territory: either as "therapeutic benefits to patients" or as "teaching topics related to the delivery of clinical care" (62). A similar separation of epistemic value occurs in Oxley and Macnaughton's study. They note how "perhaps, if the meaning of breathlessness is taken as a primary concern, we can gain key insights of how to improve the ways dyspnoea is perceived and managed by those who live with it" (260). This hints, especially in the tentative use of "perhaps", at the implicit clash between what they term the "meaning" produced by social science and humanities research, and the interests of the medical sciences in treatment and management. There is, then, a recognition here that the utility of knowledge is as key as its new emergence. What is apparent from both projects is that disciplinary restrictions can often undermine attempts at new methodologies which would offer a richer ecology of new knowledge - often because such new ways of working would not be considered bona fide research and the knowledge gained would be unable to make persuasive truth-claims. At its best, this sort of work not only attends to shared problems but also to the rough edges of common and mutually exclusive approaches to those problems.

\section{A Manifesto for the ScienceHumanities}

Having worked through these valuable projects, how do we see the ScienceHumanities as continuing to shape emergent practices and disciplinary relations? We offer this concluding manifesto not as a final word, but as a generative set of conceptual principles. Thinking from and with the perspectives of the ScienceHumanities is, to put it in the most compressed way, to think about the thinking of transdisciplinary practice. More pragmatically, we see the conceptualisation of disciplinary relations as fundamental to productive future collaboration. It is vital that we understand, in the most fine-grained ways possible, every aspect of our practices and methodologies as they interact with others. If we do not, we may find ourselves unable to meet future challenges because our foundations will be less flexible than they need to be, both in space and over time. To avoid this, we offer the following ten doctrinal statements for future work. 
First, it is essential to recognise the value, and to promote the involvement, of multiple humanities and social science disciplines (or methodologies) in all engagements with the sciences. Second, the humanities, social sciences and sciences must locate themselves equally in both the conceptual and actual spaces of engagement. Third, research should be aligned with the keynotes of humanities methods just as much as with those in the sciences and social sciences; with the aesthetic, experiential, phenomenal, imaginative, subjective and linguistic. Fourth, it is valuable, therefore to work with common problems where research is equally shared and valued by all disciplinary partners. Fifth, it can be generative to choose objects of research that do not have specific disciplinary affiliations and which are open to investigations without prior hierarchies of power. Sixth, nevertheless, it remains vital to continue to recognise and defend the differences between the humanities and the sciences, especially the acceptance of particular epistemologies and their value. Seventh, this recognition is tempered by our view that all fields of scientific enquiry are open to cultural inquiry, and will remain so even as certain domains gain and lose significance. Eighth, ScienceHumanities practices should enhance the important work already taking place in specialist fields (such as the medical humanities, literature and science, and environmental humanities) by offering sharp conceptual interrogations of their frameworks and functions. Ninth, the ScienceHumanities has a global field of concern and should therefore be conscious of the diversity of global knowledge production and sensitive to the hegemony of western formations of expertise. Tenth, in this regard, collaborations of this kind should also champion the civic and political importance of ScienceHumanities work, especially to audiences beyond the academy.

Working within the parameters and aspirations set out in this manifesto, we believe that the ScienceHumanities - as a new mode of thinking, and a new way of collaborative working - represents a powerful means to confront and tackle the two key challenges we highlighted at the beginning of this article: the challenge of multiple global concerns that require multiple and likely new expertise to address them successfully and the challenge of the difficulties of collaborative working between disciplines with very different ontological and epistemological structures and beliefs. In the process, we see the ScienceHumanities carving out a territory that interrogates not only the content and practices of more than one discipline, but also the limitations, mediations, and contingencies of transdisciplinary collaboration itself.

\section{Notes}

1. The work of this article is shared equally between the three authors. 


\section{Works Cited}

AHR Roundtable: Historians and the Question of "Modernity." "Introduction.' American Historical Review, vol. 116, 2011, pp. 631-67.

Barry, Andrew, and Georgina Born, editors. Interdisciplinarity: Reconfigurations of the Social and Natural Sciences. Routledge, 2013.

Bod, Rens, "A Comparative Framework for Studying the Histories of the Humanities and Sciences." Isis, vol. 106, no. 2, 2015, pp. 367-77.

British Academy. Crossing Paths: Interdisciplinary Institutions, Careers, Education and Applications. British Academy, 2016.

Brubaker, Rogers. Trans: Gender, Race and the Micropolitics of Identity. Princeton UP, 2016.

Campbell, Philip, and Ritu Dhand. "Time for the Social Sciences." Nature, vol. 517, no. 7532,1 Jan. 2015 , p. 5.

Chakrabarty, Dipesh. "The Climate of History: Four Theses." Critical Inquiry, vol. 35, no. 2, 2009, pp. 197-222.

Collini, Stefan. Introduction. The Two Cultures, by C.P. Snow. Cambridge UP, 1993.

Durham, University of. "Centre for Medical Humanities." www.dur.ac.uk/cmh/. Accessed 21 Nov. 2017.

Ellis, Erle, Mark Maslin, Nicole Boivin, and Andrew Bauer. "Involve Social Scientists in Defining the Anthropocene." Nature, vol. 540, no. 7632, 8 Dec. 2016, pp. 192-3.

Elsevier. A Review of the UK's Interdisciplinary Research Using a Citation-Based Approach: Report to the UK Funding Bodies and MRC. Elsevier, 2015.

Fitzgerald, Des, and Felicity Callard. "Entangling the Medical Humanities." The Edinburgh Companion to the Critical Medical Humanities, edited by S. Atkinson et al., Edinburgh UP, 2016, pp. 35-48.

Gaffield, Chad. "Presidential Address: Historical Thinking, C.P. Snow's Two Cultures, and a Hope for the Twenty-First Century." Journal of the Canadian Historical Association, vol. 21, no. 1, 2001, pp. 3-25.

Gilbert, Mark A., et al. "Portrait of a process: Arts-based research in a head and neck cancer clinic." Medical Humanities vol. 42, 2016, pp. 57-62.

Gould, Stephen Jay. The Hedgehog, the Fox, and the Magister's Pox: Mending the Gap Between Science and the Humanities. Belknap, 2011.

Griffiths, Hywel M., et al., "Searching for an Anthropo(s)cene in the Uplands of Mid Wales." GeoHumanities, vol. 3, no. 2, 2017, pp. 567-79

Gunn, Simon, and Alastair Owens. "The Modern City and the Transformation of Nature: An Introduction." Cultural Geographies, vol. 13, no. 4, 2016, pp. 49196.

HEFCE, RCUK, and the British Academy. "Interdisciplinary Research: Policy and Practice." Report from the event held on 8 Dec. 2016. www.hefce.ac.uk/news/Events/2016/Name,110328,en.html. Accessed 8 Dec. 2017.

Latour, Bruno. "MOOC on Scientific Humanities." www.bruno-latour.fr/node/532. Accessed 17 Nov. 2017.

---. “An attempt at a 'Compositionist Manifesto'.” New Literary History vol. 41, no. 3, 2010, pp. 471-90.

---. Reassembling the Social: An Introduction to Actor-Network Theory. Oxford UP, 2005. 
---. "Why has critique run out of steam? From matters of fact to matters of concern." Critical Inquiry, vol. 30, no. 2, Winter 2004, pp. 225-48.

Marcuse, Peter, "Depoliticizing urban discourse: How 'we' write." Cities, vol. 44, 2014, pp. 152-6.

Marshall, John, and Julian Bleeker. "Undisciplinarity." Digital Blur: Creative Practice at the Boundaries of Architecture, Design and Art, edited by Paul Rodgers and Michael Smyth, Libri, 2010, pp. 216-23.

Nixon, Rob. Slow Violence and the Environmentalism of the Poor. Harvard UP, 2013.

Ortolano, Guy. The Two Cultures Controversy: Science, Literature, and Cultural Politics in Postwar Britain. Cambridge UP, 2009.

Osborne, Peter. "Problematizing Disciplinarity, Transdisciplinary Problematics." Theory Culture and Society, vol. 32, no. 5-6, 2015, 3-35.

Oxley, Rebecca, and Jane Macnaughton. "Inspiring change: humanities and social science insights into the experience and management of breathlessness." Current Opinion in Supportive and Palliative Care, vol. 10, no. 3, 2016, pp. 256-61.

Proctor, Robert and Londa L. Schiebinger. Agnotology: The Making and Unmaking of Ignorance. Stanford UP, 2008.

Rorty, Richard. "Science as Solidarity." Objectivity, Relativism, and Truth: Philosophical Papers Volume 1, Cambridge UP, 1991, pp. 35-45.

ScienceHumanities. Led by Martin Willis, Keir Waddington and James Castell, hosted by Cardiff University. cardiffsciencehumanities.org. Accessed 19 Dec. 2017.

Sokal, Alan, and Jean Bricmont. Fashionable Nonsense: Postmodern Intellectuals' Abuse of Science. Picador, 1998.

Snow, C.P., The Two Cultures and the Scientific Revolution. Cambridge UP, 1959.

---. "The Two Cultures: A second look." Times Literary Supplement, vol. 25 Oct. 1963, pp. 839-44.

Ulnicane, Inga. "Grand societal global challenges: fashion or paradigm shift in knowledge policies?" Europe of Knowledge. era.ideasoneurope.eu/2017/06/06/ grand-societal-global-challenges-fashion-paradigm-shift-knowledge-policies/. Accessed 24 Nov. 2017.

Walport, Mark, and Claire Craig, Annual Report of the Government Chief Scientific Advisor 2014. Innovation: Managing Risk, Not Avoiding It. Office of the Chief Scientific Advisor, 2015.

Wordsworth, William. 'Lyrical Ballads', and Other Poems, 1797-1800. Edited by Karen Green and James Butler, Cornell UP, 1992. 